\title{
Uma análise da farinheira semiartesanal a partir da cadeia operatória no Projeto de Assentamento Primavera
}

\author{
A semi artisanal farinheira analysis from the operational chain in \\ the Primavera Settlement Project
}

\author{
Fernando Henrique Ferreira de Oliveira ${ }^{1}$ \\ Luis Antonio Barone ${ }^{2}$
}

1 Geógrafo, mestrando no Programa de Pós-Graduação em Desenvolvimento Territorial e Meio Ambiente da Universidade de Araraquara. Bolsista pelo Programa de Suporte à Pós-Graduação de Instituições de Ensino Particulares da Coordenação de Aperfeiçoamento de Pessoal de Nível Superior.

2 Sociólogo, professor assistente e doutor do Departamento de Planejamento, Urbanismo e Ambiente da Faculdade de Ciências e Tecnologia da Universidade Estadual Paulista.

\begin{abstract}
Este trabalho estudou as dimensões do patrimônio cultural e dos saberes tradicionais no assentamento rural Primavera, situado em Presidente Venceslau (SP). Buscamos entender o contexto histórico-geográfico do Pontal do Paranapanema, caracterizado pelo conflito fundiário, além de levantar elementos que carregam esse valor patrimonial, tanto de ordem material (como a farinheira semiartesanal) quanto imaterial. Este estudo compreende a importância do patrimônio imaterial na transformação do espaço dos assentamentos, desenvolvendo um novo modo de vida carregado de memórias e significados culturais. A pesquisa teve como objetivo identificar aspectos da patrimonialidade cultural nos assentamentos de reforma agrária. Em relação à metodologia, fundamentamos a investigação sob o prisma da pesquisa qualitativa, da descrição da cadeia operatória e do inventário de bens, buscando identificar elos com o modo de vida dos assentados. A observação participante, utilização de diários de campo, entrevistas e documentário fotográfico foram fundamentais para coleta e sistematização dos dados e informações coletadas.

Palavras-chave: patrimônio cultural, assentamentos rurais, cadeia operatória.
\end{abstract}

This work studied the dimensions of cultural heritage and of the traditional knowledge in the rural settlement Primavera located in Presidente Venceslau, São Paulo, Brazil. We aimed at understanding the historic-geographic context of the region of Pontal do Paranapanema, characterized by the agrarian conflict, and also to gather elements that carry this heritage value, both of material (such as the semiartisanal flour machine) and immaterial categories. This study comprehends the importance of immaterial heritage in the transformation of the space of settlements, developing a new way of life, filled with memories and cultural significance. The objective of the research is to identify aspects of cultural patrimoniality in the agrarian reform settlements. In relation to methodology, we founded the investigation on the perspective of qualitative research, the description of the operational chain and the inventory of assets, aiming at identifying links with the way of life of the settlers. The participant observation, utilization of field journals, interviews and photographic documentary were fundamental for the collection and systematization of obtained data and information.

Keywords: cultural heritage, rural settlements, operational chain 


\section{INTRODUÇÃO}

Este trabalho objetiva analisar algumas dimensões do patrimônio cultural e dos saberes tradicionais (re)produzidos no cotidiano das famílias assentadas, na região do Pontal do Paranapanema, oeste do estado de São Paulo

A pesquisa investigou os espaços de produção e reprodução dos saberes tradicionais no Projeto de Assentamento Primavera (Presidente Venceslau/SP). Assim, investigaram-se o espaço rural e a questão agrária local através da cultura popular e do patrimônio cultural. Este trabalho compreende a importância do patrimônio cultural na transformação do espaço dos assentamentos em "lugares", ambiente de um novo modo de vida, carregado de memória e ressignificação da cultura tradicional. Nesse sentido, os assentados são sujeitos com um papel importantíssimo, como guardiões e transmissores desses saberes.

Ao longo da pesquisa, identificamos diversos sujeitos que se utilizam dos conhecimentos tradicionais nos assentamentos de reforma agrária. "Sêo" José, farinheiro, exemplifica isso, pois, por meio da produção de farinha de mandioca, em sua farinheira semiartesanal, ele obtém renda e preserva um pouco da técnica produtiva e alimentar da cultura rural tradicional. Nesse caso, buscamos descrever a cadeia operatória da farinha de mandioca, que é um dos alimentos mais tradicionais e típicos da culinária brasileira.

No atual cenário da modernidade, marcado pela globalização, urbanização e industrialização, as práticas e saberes produzidos por comunidades tradicionais estão se perdendo em meio ao aglomerado e à pluralidade de informações (D'ABADIA; ALMEIDA, 2010). São poucos os espaços de manutenção dessas práticas provenientes da cultura popular. A hipótese deste estudo é a de que os assentamentos rurais ganham destaque nesse cenário de crise, pois podem ser um celeiro de reprodução desses saberes, que se materializam por meio de festas, benzedeiras, curandeiros, farinheiros, alambiques, quituteiras e contadores de histórias, sujeitos que ressignificam esses novos espaços rurais que são os assentamentos de reforma agrária.

Analisamos esses saberes a partir da cultura, tendo como ponto de partida o fato de que eles representam o patrimônio imaterial produzido pelas comunidades tradicionais que ainda resistem no território brasileiro. Podemos entender esses saberes sob as esferas da alimentação, das práticas curativas, da espiritualidade e da sociabilidade.
Temos, como segunda hipótese, que, mesmo como produtos da luta pela terra, com sujeitos de múltiplas origens, os assentamentos rurais guardam e mantêm vivos os fragmentos da cultura rural tradicional e caipira brasileira, que se reproduzem por meio das quermesses e festas comunitárias, na agricultura de subsistência, na religiosidade e nos saberes e práticas tradicionais.

Nesse sentido, realizamos o trabalho de campo no assentamento rural Primavera com a finalidade de conhecer as práticas tradicionais produzidas no assentamento e entender a organização do modo de vida dos assentados, mesmo reconhecendo que essas práticas correm o risco de desaparecer, pois seus portadores estavam morrendo.

Ao longo da pesquisa, identificamos uma farinheira em fase de transição, isto é, o proprietário estava substituindo os equipamentos antigos (de madeira) por equipamentos novos (de metal e movidos à eletricidade). Ao nos depararmos, em campo, com uma farinheira semiartesanal, que remonta a uma das práticas produtivas tradicionais desenvolvidas pelas populações rurais do Brasil, buscamos estudá-la em sua cadeia operatória (FUNARI, 2006; FACGIO, 2011). A farinheira fica no lote do "Sêo" José, um senhor de 67 anos, que aprendeu a técnica na infância com seu pai e avô.

Com o objetivo de nos apropriarmos dos aspectos relacionados ao processo produtivo da farinha de mandioca, realizamos uma entrevista, que foi gravada e transcrita para posterior análise. Do ponto de vista metodológico, a transcrição da entrevista obedeceu à abordagem utilizada por Whitaker et al. (2002), em que transcrevemos fielmente as falas do entrevistado, desde os erros de concordância até as expressões e gestos, pois estes são elementos que valorizam a entrevista. Assim, "respeitar o entrevistado implica, portanto, reproduzir apenas os erros de sintaxe, isto é, as formas peculiares de articulação do discurso. Escrever corretamente o léxico (sem erros ortográficos) nos parece fundamental para demonstrar esse respeito" (WHITAKER et al.; 2002, p. 117).

Tentou-se, posteriormente, identificar alguém que conhecesse e usasse as técnicas mais tradicionais no fabrico da farinha de mandioca; contudo, um primeiro levantamento mostrou que aqueles mais velhos, que ainda produziam mandioca em equipamentos rústicos, no geral, já haviam falecido.

Registramos, por meio de fotos, todos os equipamentos produtivos da farinheira presente no assentamento. Esse nos pareceu o melhor recurso metodológico para um inventário dessas práticas que buscamos, facilitando a posterior discussão da cadeia operatória do 
artefato, técnica derivada da arqueologia (SILVA, 2002; FUNARI, 2006; FACGIO, 2011). Evidenciamos, assim, a importância do farinheiro na manutenção dessa prática produtiva tradicional, através da sua própria descrição do método de obtenção da farinha de mandioca.

Em suma, este trabalho pretende ser interdisciplinar, pois estuda as dimensões dos assentamentos rurais a partir de temas ligados ao patrimônio cultural, à cultura popular e aos saberes tradicionais. Os assentados se inserem nesse cenário como guardiões de um patrimônio cultural precioso, pois reproduzem, em seu cotidiano, as técnicas e os conhecimentos ligados ao universo rural tradicional, ressignificando seus espaços, transformando o território em "lugares" (TUAN, 1983).

\section{Histórico do assentamento Primave- RA, no Contexto do Pontal do Parana- PANEMA}

Dentre os vários municípios que compõem o Pontal do Paranapanema, Presidente Venceslau é um dos que comportam experiências de assentamentos rurais em seu território. Contando com uma população de pouco mais de 35 mil habitantes, essa cidade tem cinco Projetos de Assentamentos (PAs), todos instalados pelo ITESP:

O PA Primavera conta com 128 lotes familiares; o PA Tupanciretã, com 72;. o PA Radar, com 29; o PA Sta. Maria, com 17; e o PA São Camilo, com 32.

Os assentamentos Primavera e Tupanciretã (mais antigos e os maiores do município) foram o nosso universo empírico. $\mathrm{O}$ assentamento Primavera teve sua origem no processo de luta pela terra que se generalizou pela região a partir do início dos anos 1990. A antiga fazenda, de pouco mais de 2 mil hectares, foi uma referência na pecuária de corte no anos 1970, entrando em decadência a partir da década de 1980 . Nesse momento, passou a ser objeto de disputa judicial por supostos herdeiros do antigo fazendeiro, um cidadão italiano falecido nessa década. Com isso, um dos demandantes judiciais passou a arrendar seus pastos, e a notável estrutura produtiva - composta por unidade de processamento de ração, silo e grande área de confinamento - foi desativada, abandonada e progressivamente depredada (BARONE; OLIVEIRA, 2014). Essas benfeitorias - que podem ser consideradas patrimônio edificado (GHIRARDELLO; SPISSO, 2008)
- compõem a paisagem do local, destacando-se mesmo como únicas no contexto da reforma agrária regional.

Figura 1. Localização do município de Presidente Venceslau, na região do Pontal do Paranapanema.

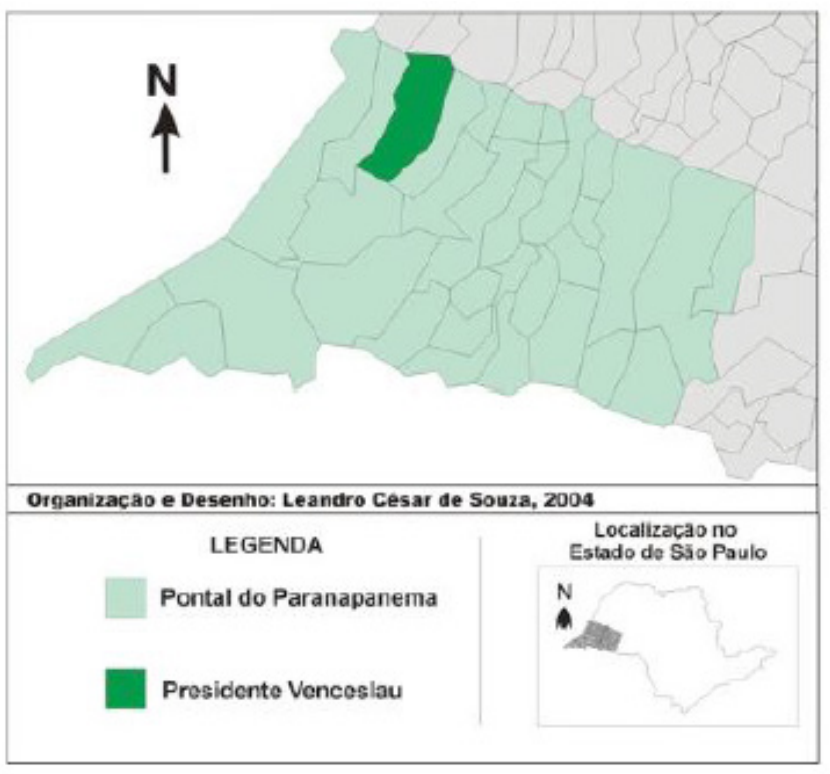

Fonte: BARONE; OLIVEIRA (2015).

Em 1996, como solução ao litígio entre os demandantes, o governo do estado, através do ITESP, incluiu a fazenda no rol das áreas arrecadadas para assentamentos. Dois diferentes grupos de sem-terras participaram do processo de pressão pela negociação/liberação da fazenda Primavera: o MST e a Associação Brasileiros Unidos Querendo Terra (ABUQT), este último um grupo de formação local, composto, sobretudo, por arrendatários e ex-arrendatários da própria Fazenda Primavera. Isso explica a divisão (hoje, com sentido estritamente administrativo) da fazenda em dois assentamentos: Primavera I e II. A constituição de grupos associativos entre os assentados tratou de misturar trabalhadores dos dois movimentos, que, de resto, pouca incidência têm, atualmente, no interior desse PA. A finalização de sua implantação (os trabalhadores ocuparam a área em 1996) deu-se no início de 1998 (OLIVEIRA, 2015).

O patrimônio cultural nos assentamentos de reforma agrária

A noção de patrimônio surge, no final do século XIX, associado à construção de igrejas barrocas, grandes palácios e outros monumentos produzidos pela elite europeia. Nesse contexto, a questão do patrimônio atrelou-se ao poder da igreja e elite, entendido como herança social, deixada de pai para filho. 
Entende-se o patrimônio como um "conjunto de bens, de natureza material e/ou imaterial, que guarda em si referências à identidade, a ação e a memória dos diferentes grupos sociais" (GHIRARDELLO; SPISSO, 2008, p. 13). O patrimônio é um dos elementos importantes de desenvolvimento na questão da promoção cultural, do bem-estar social e da cidadania. Entretanto, o patrimônio se faz presente nas formas de expressão; literatura, música, danças, teatro, cinema, entre outras.

Segundo Ghirardello e Spisso (2008), o patrimônio se divide em quatro tipos:

1. Patrimônio cultural tangível: é aquele composto por bens materiais, ramificando-se em bens móveis, como mobiliários, utensílios, obras de arte, documentos etc. Bens imóveis são os que não possuem qualquer tipo de mobilidade, como os monumentos, sítios arqueológicos e elementos naturais que tenham significado cultural.

2. Patrimônio cultural intangível: é aquele constituído por bens de natureza imaterial; costumes, lendas, rituais, músicas etc.

3. Patrimônio natural: é constituído por bens que não tenham sofrido interferência humana em sua construção. Ex: grutas, montanhas, rios, animais silvestres, ecossistemas etc.

4. Patrimônio edificado: composto por edificações construídas pela ação humana, com suas peculiaridades e significados culturais. Ex: casas, cidades, monumentos.

Por causa da importância histórica e cultural do patrimônio, diversas ações e intervenções de resguarda vêm sendo promovidas ao longo dos últimos anos, como a criação de uma legislação que tem como objetivo preservá-lo.

Ghirardello e Spisso escrevem que o reconhecimento do patrimônio se define como um conjunto de ações, realizadas pelo poder público e alicerçadas por legislação específica, que visam a preservar os bens de valor histórico, cultural, arquitetônico, ambiental e afetivo, impedindo sua destruição e/ou descaracterização|| (GHIRARDELLO; SPISSO, 2008, p. 15). Acredita-se que o patrimônio cultural se qualifica como um conjunto de bens materiais e imateriais que devem ser protegidos e resguardados pela União e pela comunidade em geral, por causa de sua importância artística, histórica e cultural.
Os sujeitos inseridos nos projetos de reforma agrária são de diversas origens: desde o lavrador que sempre esteve no meio rural até o proletário que vive na cidade. No entanto, todos buscam, no campo, um estilo de vida característico do modo de ser rural, reproduzindo gestos e conhecimentos tradicionais, como o uso de plantas e raízes para fins curativos, receitas de quitutes e a presença de farinheira artesanal, contribuindo para preservação e permanência desses conhecimentos tradicionais.

Os assentamentos rurais seriam, então, espaços de manutenção de conhecimentos e saberes produzidos por culturas tradicionais detentoras de um modo de ser e estar, e um conjunto de "saber-fazer" sobre a natureza e o mundo sobrenatural, que é transmitido de geração em geração por meio da oralidade. São, portanto, possíveis celeiros de um patrimônio cultural a ser conhecido, valorizado e protegido.

\section{A FARINHEIRA DE MANDIOCA COMO PATRIMÔNIO ALIMENTAR DA CULTURA BRASILEIRA}

A farinha é um dos principais produtos da mandioca, e seu uso é variado e difundido em diversas regiões do país, fazendo parte das refeições de muitos brasileiros. Segundo Chisté e Cohen (1999), a mandioca (Manihot esculenta Crantz) desempenha um importante papel na dieta alimentar dos brasileiros, por seu alto teor energético. Nesse sentido, o Brasil figura como um dos maiores produtores e consumidores dessa cultura no cenário internacional.

Desde o período pré-colonial brasileiro, tem-se a mandioca como uma das fontes de alimentação da dieta humana e animal. Durante esse período, os índios a domesticaram e passaram a inseri-la em sua alimentação cotidiana. Segundo Cascudo (2000), "a cultura da mandioca fixou o indígena nas áreas geográficas de sua produção e possibilitou a colonização do Brasil pela adaptação do estrangeiro a essa alimentação" (CASCUDO, 2000, p. 544).

A mandioca marca a história da alimentação brasileira, sendo uma comida presente desde sempre na mesa dos brasileiros. No meio rural, esse alimento exerce importante influência, por alimentar e gerar renda para milhares de famílias agricultoras. Para Chisté e Cohen (1999), os produtores rurais detêm todo o conhecimento prático da fabricação da farinha de mandioca. 
Nesse sentido, a farinha é resultante do aproveitamento da raiz de mandioca brava e seu processo de fabrico representa uma atividade importante de reprodução e manutenção de práticas tradicionais que configuram as populações rurais brasileiras. Ou seja, a utilização de técnicas como a do fabrico da farinha, além de gerar renda, promove a preservação de saberes tradicionais que necessitam de resguardo por parte da sociedade brasileira. Ainda segundo Chisté e Cohen:

A mandioca é originária do Brasil, da região amazônica fronteiriça com a Venezuela e se constitui em alimento energético para mais de 400 milhões de pessoas no mundo, sobretudo nos países em desenvolvimento, onde é cultivada por pequenos agricultores, em áreas reduzidas e com baixa produtividade (CHISTÉ; COHEN, 1999, p. 12).

A mandioca possui alto teor de amido e é cultivada na América Tropical há mais de 5.000 anos, domesticada por grupos humanos agricultores. Essa cultura difundiu-se para outros continentes por meio da metrópole portuguesa, que levou a mandioca para Europa, África Oriental e Ásia (CHISTÉ; COHEN, 1999).

Segundo Chisté e Cohen(1999), o Brasil é o segundo maior produtor de mandioca do mundo, produzindo 24,2 milhões de toneladas anuais, o que coloca essa cultura entre as principais do país. A principal produtora do mundo é a Nigéria, que produz cerca de 32 milhões de toneladas. A cultura de produção de mandioca geralmente ocorre em países subdesenvolvidos ou em desenvolvimento, por causa da forte presença da agricultura de subsistência.

A maior parte da mandioca brasileira destina-se à produção de farinha de mandioca (mandioca brava). O Brasil é o único país da América Latina que consome farinha de mandioca em quantidades expressivas (CHISTÉ; COHEN, 1999). Essa cultura não possui um mercado de exportação significativo.

A farinha de mandioca é um produto exclusivamente brasileiro, na medida em que muitas regiões produtoras de mandioca, como a Ásia, desconhecem a existência desse alimento. Para Cascudo (2000), a farinha de mandioca é um dos alimentos mais importantes de nossa alimentação, considerada o "pão dos brasileirost|". Segundo esse autor, a farinha, de fácil produção e conservação, possibilitou a penetração no sertão brasileiro. "O português e o negro africano habituaram-se rapidamente à farinha como alimento indispensável (e às vezes único), podendo independer das exigências mais complexas do estômago" (CASCUDO, 2000, p. 387).
No cenário atual, a mandioca destaca-se como importante produto da agricultura familiar, pois muitas famílias inseridas no meio rural sobrevivem da venda e do consumo desse produto.

Segundo Chisté e Cohen (1999), o processo produtivo da farinha de mandioca ocorre por meio de nove etapas: colheita, lavagem, descascamento, prensagem, esfarelamento, torração, empacotamento, pesagem e armazenamento.

Os equipamentos utilizados no processamento da farinha são: lavador, ralador, forno, peneira e prensa.

\section{IMPORTÂNCIA DO MODO DE VIDA CAIPIRA E TRADICIONAL RURAL NA HISTÓRIA DA ALIMENTAÇÃO BRASILEIRA}

Conforme visto em Antonio Candido (1987), a influência da cultura caipira e rural tradicional é de fundamental importância para o entendimento da história da alimentação brasileira. Ao analisar as condições de vida do caipira paulista do século passado, o autor aborda dois termos relevantes para compreensão desse sujeito na sociedade brasileira: a cultura caipira e a cultura rústica. Nesse sentido, o autor escreve que:

O termo rústico é empregado aqui não como equivalente de rural, ou de rude, tosco, embora os englobe. Rural exprime localização, enquanto ele pretende exprimir um tipo social e cultural, indicando o que é no Brasil o universo das culturas tradicionais do homem do campo, as que resultarem do ajustamento do colonizador ao Novo Mundo, seja por transferência e modificação dos traços da cultura original, seja em virtude do contato com o aborígene (CÂNDIDO, 1987, p. 21).

O termo rústico relaciona-se ao modo de vida caboclo, tipo étnico decorrente da miscigenação do índio com o colonizador, ou seja, define-se por condições étnicas e culturais do contato dos portugueses com os nativos e o novo meio. Em contrapartida, utiliza-se a expressão "caipira" para designar os aspectos culturais dos grupos tradicionais que ocuparam o espaço rural no contexto paulista. Portanto, usa-se esse termo para definir um modo de vida, um modo de ser dos sujeitos que vivem no campo, e jamais no sentido de tipo racial. 
Percebe-se que há uma visão errônea e preconceituosa do estilo de vida caipira, pois esse modo de vida tradicional muitas vezes é encarado como estágio primitivo e atrasado da formação da sociedade brasileira. No Dicionário do folclore brasileiro, escrito por Câmara Cascudo (2000), a expressão "caipira” significa:

homem ou mulher que não mora na povoação, que não tem instrução ou trato social, que não sabe vestir-se ou apresentar-se em público. Habitante do interior, canhestro e tímido, desajeitado, mas sonso. Nome com que se designa ao habitante do campo (CASCUDO, 2000, p. 223).

Dialogando com essa definição, Wanderley (2011) escreve que a mídia em geral contribui para reforçar essa visão, pois diversos interesses camuflam as grandes questões sociais a serem debatidas pela sociedade brasileira. No que diz respeito ao espaço rural e à questão agrária, a autora diz que, na TV, veicula-se uma imagem distorcida da cultura camponesa, pois, quando esses sujeitos aparecem, são colocados como "pobres caipiras, distribuindo milho às galinhas no terreiro a volta da casa e que, com forte sotaque, expressavam sua identificação a um mundo rural atrasado" (WANDERLEY, 2011, p. 21).

Ao estudar as condições de vida caipira do século passado, Candido (1987) se apoia nos elementos diretamente ligados à manutenção da vida e à exploração dos recursos naturais, para elaboração da dieta dessa cultu$\mathrm{ra}$, considerando que esses fatores permitem compreender as formas de vida social, manutenção dos saberes e sobrevivência desses grupos na sociedade brasileira.

A cultura caipira soube adaptar-se ao território paulista, na medida em que possuía conhecimentos tradicionais para explorar, de maneira inteligente, os recursos naturais disponíveis para sua sobrevivência, além de manter uma relação ecológica com a natureza. Pois:

\footnotetext{
A sociedade caipira tradicional elaborou técnicas que permitiram estabilizar as relações do grupo com o meio (embora em nível que reputaríamos hoje precário), mediante o conhecimento satisfatório dos recursos naturais, a sua exploração sistemática e o estabelecimento de uma dieta compatível com o mínimo vital - tudo relacionado a uma vida social de tipo fechado, com base na economia de subsistência (CANDIDO, 1987, p. 36).
}

Antes mesmo da colonização portuguesa, o território paulista era densamente povoado por grupos indígenas agricultores: Guaranis, Caiapós, Caingangues e
Xavantes. No entanto, a intensificação do povoamento no estado de São Paulo se deu a partir das bandeiras, durante o século XVI, caracterizando-se pelo nomadismo e exploração predatória dos recursos naturais. Sobre a ocupação do território paulista, Faccio (2011) escreve que:

No início do período colonial, São Paulo vivia da agricultura de subsistência, aprisionando índios para trabalharem como escravos na frustrada tentativa de implantação, em escala, da lavoura de cana-de-açúcar. Na segunda metade do século XVI, começariam as viagens de reconhecimento ao interior do país, as "bandeiras", expedições organizadas para aprisionar índios e procurar pedras e metais preciosos nos sertões distantes, dando início ao levantamento de terras desconhecidas (FACGIO, 2011, p. 20).

Considera-se o processo de formação da sociedade paulista dos séculos XVI ao XVIII por meio das relações interétnicas dos colonizadores portugueses com os índios nativos do território. A partir dessa sociabilidade e ocupação do meio, é possível definir a economia seminômade que marcou a alimentação e comportamento do paulista.

A figura do caipira emerge nesse contexto de ocupação e expansão do território do estado de São Paulo, marcado pelo "desenvolvimento das técnicas de orientação, defesa e utilização do meio natural, tomadas ao indígena pelo conquistador" (CANDIDO, 1987, p. 36).

Portanto, sabe-se que a cultura caipira possui heranças das relações interculturais dos séculos XVI, XVII e XVIII. O nomadismo, a caça e a coleta dos indígenas, atrelada aos traços da cultura colonizadora, condicionou a vida social do caipira. "Por isso, na habitação, na dieta, no caráter do caipira, gravou-se para sempre o provisório da aventura" (CANDIDO, 1987, p. 37).

Para Gomes (2011), as mulheres assentadas utilizam conhecimentos tradicionais no cotidiano, em relação aos cuidados com a alimentação, saúde e reprodução da vida. O espaço doméstico é o principal local em que são preservados/transmitidos esses conhecimentos. Portanto, esse espaço, entendido como a casa e a cozinha, funcionam como lugares de manutenção e transmissão de receitas tradicionais, pois "a dimensão da cozinha é um lugar tradicionalmente atribuído à mulher ao longo da história, [...] [e] ressaltar os aspectos importantes dessa história necessariamente passa pela dimensão da alimentação" (GOMES, 2011, p. 36).

Entende-se a casa e a cozinha não apenas como espaços ligados à segurança alimentar e ao consumo, mas pela dimensão cultural que caracteriza diferentes grupos 
sociais, que mantêm suas receitas de quitutes, garrafadas e chás, transformando essas tradições em patrimônio. Determina-se a dieta de um grupo não apenas por fatores ambientais e econômicos, ligados à disponibilidade de itens, mas também por seu valor cultural, a partir da mentalidade, dos ritos, valores éticos e religiosos. As receitas tradicionais são vistas como herança cultural, transmitidas de mãe para filha em determinada cultura.

Além do mais, o processo de realização dessas receitas leva em conta o desperdício, o cuidado, a criatividade e a cultura regional da mulher. A partir das receitas tradicionais, percebe-se como a memória é fundamental na manutenção e permanência da cultura e na construção do patrimônio cultural dos grupos humanos. É preciso destacar ainda os lugares de atuação das mulheres, como o quintal e a cozinha, como espaços de reprodução social, que têm por base a conservação das práticas sociais tradicionais (GOMES, 2011, p. 42).

Com o processo de modernização, urbanização e inserção das mulheres no mercado de trabalho, os saberes tradicionais produzidos e conservados por elas acabaram sendo esquecidos e desvalorizados pela sociedade. Porém, quando se estuda a agricultura familiar, eles são importantes manifestações do patrimônio imaterial brasileiro (GOMES, 2011).

\section{A FARINHEIRA DO ASSENTAMENTO Primavera E A SUA CADEIA OPERATÓRIA}

No assentamento Primavera, encontramos uma farinheira artesanal em um lote. O dono da farinheira é o "Sêo" José, de 67 anos. Para ele, essa técnica funciona como fonte de obtenção de renda, além de representar a memória de seus antepassados, uma vez que ele aprendeu a produzir farinha de mandioca com seu pai e avô.

Conversamos com ele sobre o processo produtivo da farinha tradicional, a obtenção da mandioca, os equipamentos e o escoamento da produção. Iniciamos a entrevista com uma pergunta a respeito do processo produtivo da farinha no lote. Sobre se produz hoje ou não, "Sêo" José respondeu:

Então, a máquina tá em reforma. né? Geralmente eu fabricava aqui doze sacas de farinha por dia, farinha boa, bem feita e bem trabalhada. Agora com o maquinário novo, ela vai ter potência, se for o "mêmo" trabalhador, d'eu produzir dezoito sacas por dia. ("Sêo" José, em 05/2014).

Percebe-se que, mesmo sendo uma técnica tradicional, entende-se o uso da farinheira a partir de um viés econômico, que permite a obtenção de renda. No lote do "Sêo" José, o maquinário tradicional está quebrado e, em breve, será substituído por equipamentos modernos, movidos à eletricidade, possibilitando o crescimento em $50 \%$ na produção da farinha de mandioca, passando de 12 para 18 sacas ao dia. Cada saca pesa 50 quilos.

O "Sêo" José trabalha há 5 anos com a farinheira. Porém, conhece o uso da técnica desde a infância, quando aprendeu com seu pai. Quando perguntamos sobre o funcionamento da farinheira, Seu José respondeu: "Aqui rapava na mão, na faca, depois botei um lavador aqui. A prensa é essa daqui que serve pra enxugar a massa. Isso aí até uma criança mexe com ela" "Sêo"José, em 05/2014).

Em relação à obtenção da mandioca, o "Sêo" José disse que planta metade em seu lote e pega a outra com o sócio. Perguntado sobre quanto de mandioca é necessário para produzir 18 sacas por dia, ele respondeu: "Óia, $1.000 \mathrm{~kg}$ de mandioca, agora nessa data que nóis tá, dá $350 \mathrm{~kg}$ de farinha" (entrevista realizado no assentamento Primavera, com "Sêo" José, em 05/2014). A cada tonelada de mandioca, produzem-se $350 \mathrm{~kg}$ de farinha pronta. Ou seja, 35\% da mandioca efetivamente se torna farinha.

O escoamento da produção ocorre dentro do próprio assentamento, o que indica comércio comunitário, marcado pelas relações de vizinhança, dentro do assentamento. "Sêo" José afirma que, "vende aqui mesmo, pra um e pra outro". Em relação ao preço da farinha, afirma que vende a $\mathrm{R} \$ 3,00$ reais o saco de um quilo. Segundo ele, venderia hoje a $\mathrm{R} \$ 150,00$ a saca de $50 \mathrm{~kg}$.

Adquiriu-se a farinheira antiga e manual por meio de uma sociedade com dois colegas de "Sêo" José. Porém, com a farinheira funcionando, ele percebeu que os colegas não dominavam a técnica e não se empenhavam no trabalho, pois a farinha produzida era queimada, por ser de má qualidade. Por isso, arrependeu-se de ter se juntado aos colegas:

A farinheira velha comprei em sociedade com mais dois colegas. Me arrependi, porque o caboclo fazia 200 sacas de farinha, mas não sabia trabalhar direito. Aí, eu num podia ensinar uma coisa que o caboclo 
não me pedia. Se ele vier pedir pra eu ensinar, eu ensino, se não, eu digo nada, não. Ele fazia uma farinha azeda, queimada, de qualquer jeito. Pra vender foi o maior "trabái" do mundo. Aí, um dia, ele chegou e disse: "me compra a minha parte?". Eu falei: eu compro, vou fazer o quê. Quanto você quer? Aí ele me falou. As condições de me pagar é essa aqui. Aí, tá feito o negócio. Aí, comprei a parte dele. Aí, parte do outro anda tá aqui, mas o outro "desaconsoou", "num qué" nada. ("Sêo"José, em 05/2014).

Com o tempo, "Sêo" José comprou a parte de um dos sócios e o outro abandonou o ramo da farinheira, deixando os equipamentos para ele. Questionado sobre o sumiço do sócio, "“’"Sêo" José respondeu:

Não, depois ele falou: vou plantar mandioca e tu faz a meia pra "nóis". O ruim é que ele tem uma herança aqui ainda, né? "Mas num tá bom"? Tá bom, "uai". Então, "nóis podia" ter pensado na hora da “comprá" essa farinheira ("Sêo" José, em 05/2014).

"Sêo" José pagou cerca de $\mathrm{R} \$ 9.000,00$ na aquisição dos equipamentos antigos. Essa farinheira é composta por um lavatório, uma prensa, um triturador e um forno.

De posse das informações dadas pelo "Sêo" José, fizemos um estudo da produção da farinha semiartesanal ali fabricada, por meio da cadeia operatória do artefato. Essa abordagem busca entender o artefato em sua totalidade, desde o início da produção, a escolha da matéria-prima, o processo de fabrico, o seu uso e função, a reciclagem e o descarte no ambiente, finalizando o processo (SILVA, 2002).

Segundo Silva (2002), a cadeia operatória define-se como uma série de operações envolvidas em qualquer transformação da matéria por seres humanos. "O artefato, por outro lado, não é apenas um indicador de relações sociais, mas, enquanto parte da cultura material, atua como direcionador e mediador das atividades humanas" (FUNARI, 2006, p. 33).

Após a colheita da mandioca, as raízes devem ser lavadas no tanque feito de alvenaria (FIGURA 2), com o objetivo de retirar a terra presente na casca, eliminando as impurezas que prejudicam a qualidade da mandioca. A água utilizada deve ser de boa qualidade, para não contaminar a mandioca.
Figura 2. Lavatório da mandioca, após a colheita.

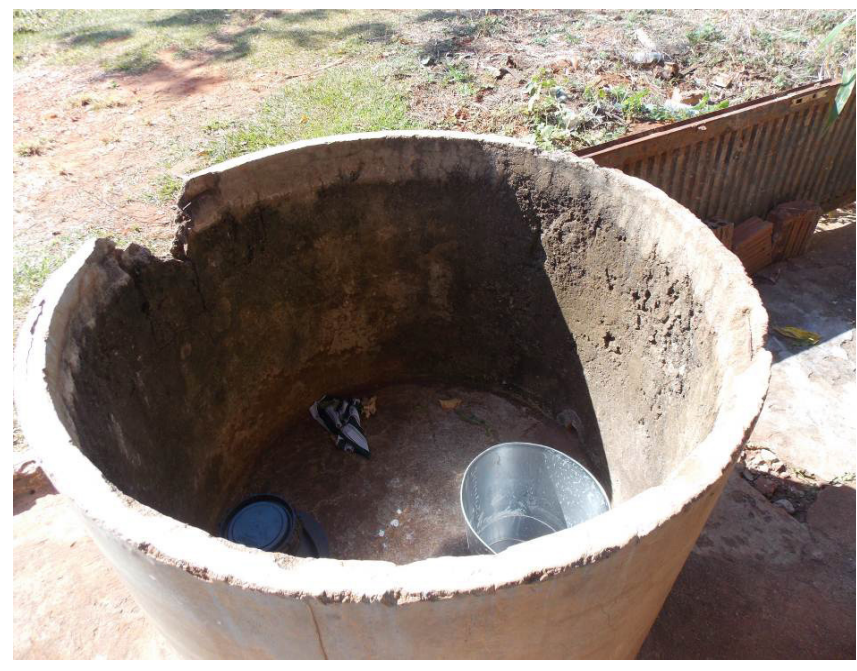

Fonte: Registrada pelos próprios autores, em trabalho de campo (abril de 2014).

O descascamento da raiz compreende a segunda etapa, podendo ser feito manualmente, com facas e raspador, ou mecanicamente, por meio do descascador cilíndrico (presente no maquinário novo). Para Chisté e Cohen, "o descascamento elimina as fibras presentes nas cascas, as substâncias tânicas, que escurecem a farinha, e parte do ácido cianídrico que se concentra em maior proporção nas entrecascas" (CHISTÉ; COHEN, 1999, p. 27).

Após as etapas da lavagem e do descascamento, levam-se as raízes para um ralador. Realiza-se a ralação a seco, sem adição de água. Coloca-se a massa obtida em um tanque, para posteriormente prensá-la em uma prensa feita numa estrutura artesanal de madeira e ferro (FIGURA 3).

Após o tanque, colocam-se os sacos com a massa obtida na prensa e repete-se o processo sucessivamente até que se atinja determinada quantidade, para depois se prensar. O tempo de prensagem depende do equipamento, mas não deve passar de duas horas, para que a massa não fermente. Durante essa etapa, a massa perde cerca de 20 a 30\% de água, que contém de 5 a 7\% de seu volume em amido (CHISTÉ; COHEN, 1999). 
Figura 3. Prensa da farinheira artesanal.

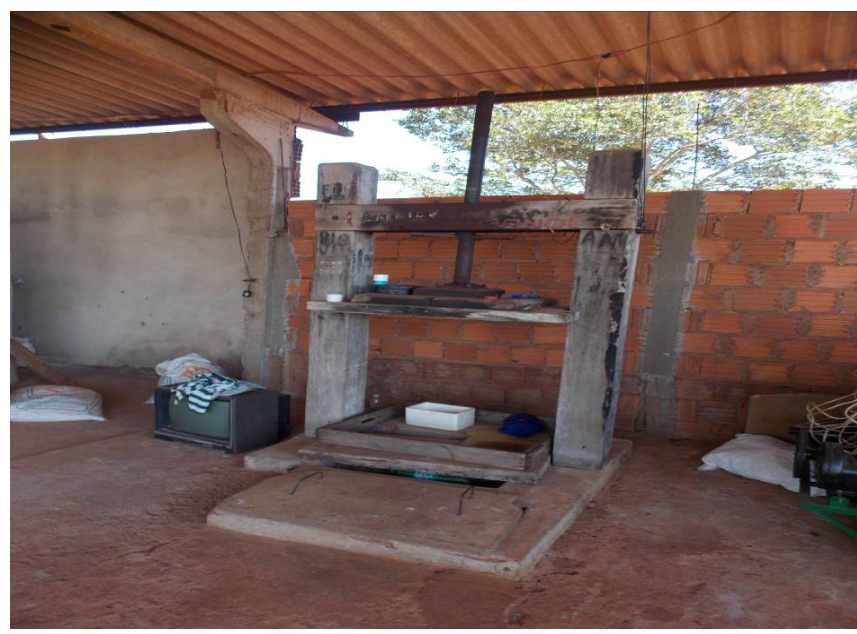

Fonte: Registrada pelos próprios autores, em trabalho de campo (abril de 2014).

Ainda segundo Chisté e Cohen:

A prensagem deve acontecer logo após a trituração, para impedir a fermentação e o escurecimento da farinha. É realizada em prensas manuais de parafuso ou em prensas hidráulicas e tem como objetivo reduzir, ao mínimo possível, a umidade presente na massa triturada para impedir o surgimento de fermentações indesejáveis, economizar tempo e combustível na torração, e possibilitar uma torração sem formação excessiva de grumos (CHISTÉ; COHEN, 1999, p. 30).

Terminada a prensagem, a raspa obtida se apresenta em forma de blocos compactos. É necessário, então, o esfarelamento desses blocos. Esse processo ocorre de forma manual e/ou mecânica. No caso da farinheira artesanal, realiza-se manualmente o esfarelamento quando se coloca a massa prensada sobre uma peneira, passando-se o rodo repetidamente para quebrar os blocos.

No caso de processo mecânico, "utiliza-se peneira vibratória com motor elétrico, opção que melhora a eficiência do processo, a rentabilidade da matéria-prima e a otimização dos custos, além de elevar a qualidade do produto" (ARAÚJO; LOPES, 2008, p. 17). A farinheira estudada tem seu esfarelamento feito de forma mecânica (FIGURA 4).
Figura 4. Esfarelador da farinha de mandioca.

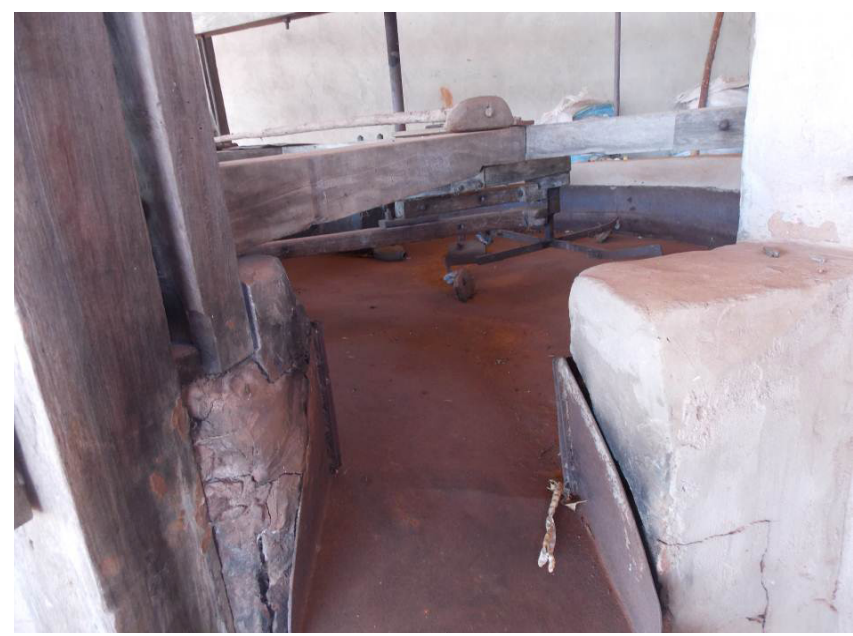

Fonte: Registrada pelos próprios autores, em trabalho de campo (abril de 2014)

Segundo esses autores, é imprescindível a separação dos blocos mais grosseiros, dos pedaços de raízes e cascas que não foram trituradas completamente, de modo a garantir a produção de farinha mais fina. Assim como a prensa, produz-se o esfarelador numa estrutura artesanal de madeira e ferro.

Após a etapa do esfarelamento, deve-se conduzir a massa ao forno, para secar, até atingir cerca de $14 \%$ de umidade, de modo a deixá-la mais crocante. Segundo Araújo e Lopes (2008), levam-se, em média, 30 minutos na torração da massa. Esse processo ocorre:

[...] com o forneiro mexendo a massa com o auxílio de um rodo de madeira, de cabo longo e liso, até a secagem final da farinha, em torno de $13 \%$ de umidade. Com a perda de umidade e secamento promovido pela torração, ocorre também o clareamento da massa. Na produção artesanal de farinha Brasil afora, os fornos são construídos do lado de fora da casa de farinha (ARAÚJO; LOPES, 2008, p. 12).

No caso da farinheira de "Sêo" José, a farinha pronta demora, em média, duas horas para sair do forno (FIGURA 5). 
Figura 5. Entrada do forno artesanal, lote "Sêo" José

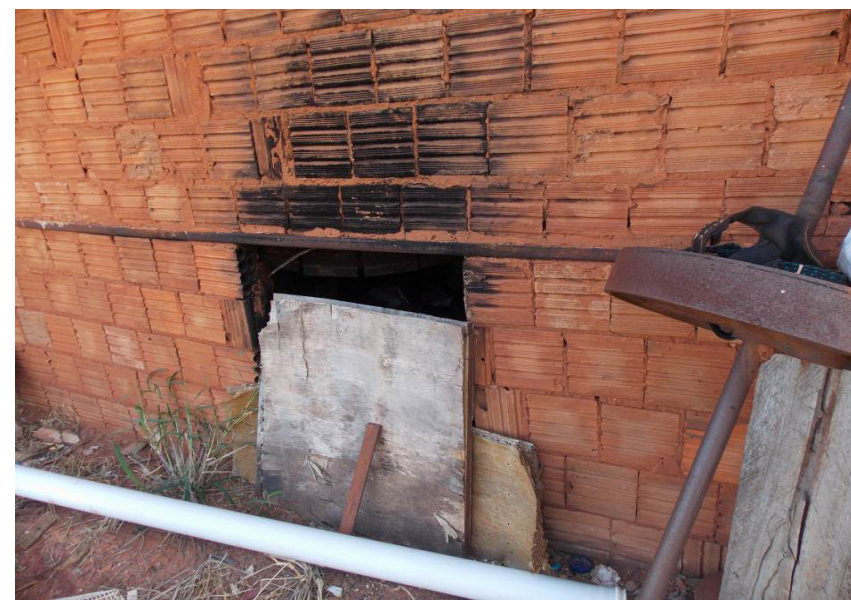

Fonte: Registrada pelos próprios autores, em trabalho de campo (abril de 2014).

A pesagem (FIGURA 6) e o armazenamento compreendem as últimas etapas do processo produtivo da farinha de mandioca.

Figura 6. Balança de pesagem da farinha.

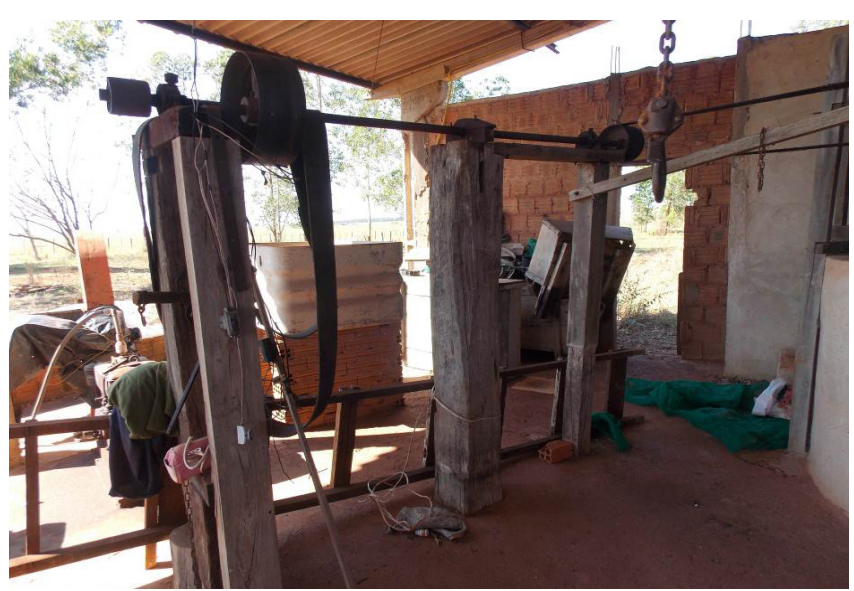

Fonte: Registrada pelos autores em trabalho de campo (abril de 2014).

Questionado sobre os investimentos no maquinário novo, "Sêo" José disse que investiu sozinho, sem ajuda de financiamento, e que foi necessário vender alguns animais de sua propriedade, para investir nos equipamentos. Perguntamos, então: "Precisou de financiamento?". Ele respondeu:

Não, não! Precisava, mas, a turma não arruma o "dinheirinho". Dinheiro é a coisa mais difícil! Aí, eu vendo um animal, um boi daqui, um porco dali, e tô tocando né? ("Sêo" José, em 05/2014).
A esposa do farinheiro não está muito animada com o negócio do "'marido, pois se realizaram muitos investimentos e tentativas de levar a farinheira para frente; contudo, ela continua estagnada há tempos. Para a esposa, a farinheira é um investimento desnecessário, pois, no momento, não gera renda. Ela ainda argumenta: "Eu digo pra ele: "ocê" tá é só de gastar o dinheiro e deixar esse negócio amontoado aí. "Não trabalha, fica parada aí" (M., esposa de "Sêo" José, em 05/2014).

Em relação à farinheira mecanizada, "Sêo" José disse que saiu $50 \%$ mais barata, cerca de $\mathrm{R} \$ 4.500,00$, incluindo todos os equipamentos. A farinheira modernizada custou metade do investimento na farinheira manual (FIGURAS 7 e 8). O forno novo custará mais $\mathrm{R} \$ 1.500,00$. Segundo ele:

É, agora vai vim mais um forno, que o rapaz que trabalha de verdade tá fazendo pra mim, que custa mais 1.500,00, pra tirar esse e colocar o outro. Aí vai vim uma máquina dessa aqui, que é um quebrador de massa, "maiorzinho" que esse, que ele ainda não falou o preço. Aí depois desse quebrador de massa, ele vai me fazer mais duas peneiras pra trabalhar a farinha pronta. Isso aqui vou gastar mais ou menos uns 10.000,00 nessa reforma aí. Só que eu também tô descontando o que eu não ganhei ano passado porque a máquina tava quebrada e eu tava doente. Plantando esse ano, eu ganho esse dinheiro numa colheita, esses 10.000,00. E pago todo mundo que "trabaiá" ("Sêo" José, em 05/2014).

Figura 7. Prensa da farinheira mecanizada.

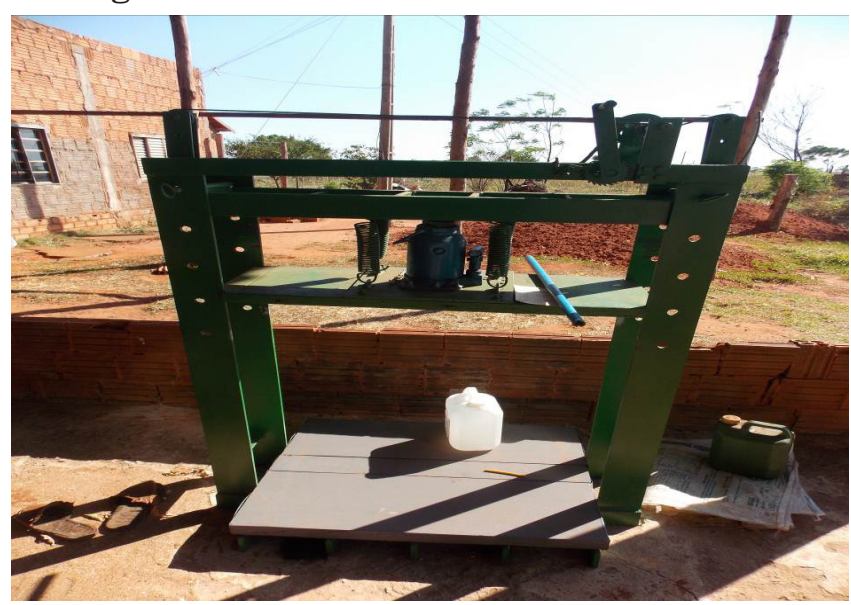

Fonte: Registrada pelos próprios autores, em trabalho de campo (abril de 2014). 
Figura 8. Triturador mecânico.

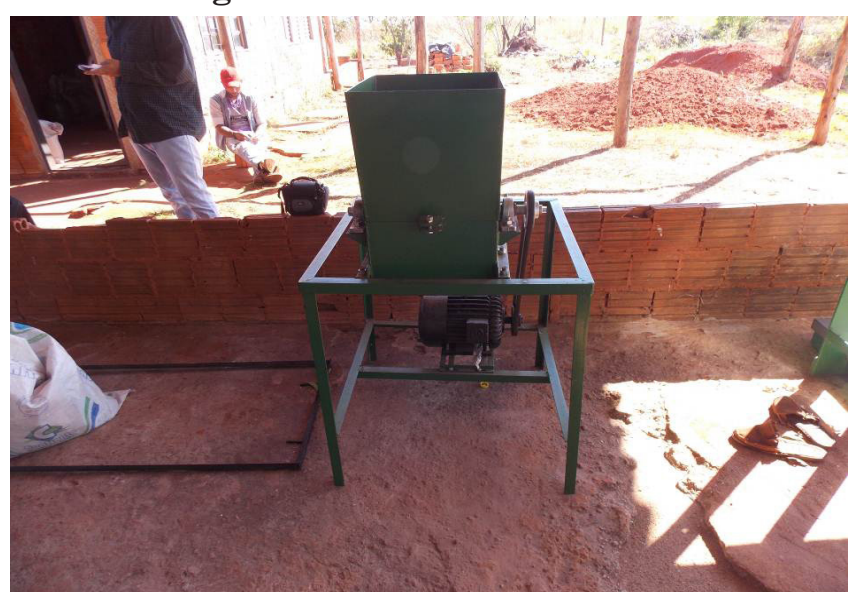

Fonte: Registrada pelos próprios autores, em trabalho de campo (abril de 2014).

Perguntamos ao "Sêo" José sobre o período de colheita da mandioca:

- É noventa dias só, pra dá farinha boa.

- De que mês a que mês?

- Começa mês passado, que passou.

- Junho, julho e agosto.

- É isso, isso!

- E o resto do ano para?

- Para, porque a farinha não tá boa, a farinha tá cansada, tá fraca.

De maneira geral, percebemos que "Sêo" José é um dos sujeitos do assentamento que, mesmo de maneira inconsciente, reproduz práticas tradicionais do universo rural tradicional. O seu lote é um espaço de manutenção dessas técnicas tradicionais, no qual a farinheira representa um símbolo de permanência dessa cultura dentro do assentamento.

No entanto, a farinheira do "“'Sêo” José será substituída por um novo maquinário, moderno e mecanizado, de modo a possibilitar o aumento da produtividade. Isso é reflexo do atual cenário da modernidade em que estamos inseridos, na qual os conhecimentos, crenças, costumes e tradições vêm sendo desvalorizados e apagados da história da cultura popular brasileira.

Nesse sentido, discutimos o papel da farinheira artesanal como técnica produtiva tradicional da cultura rural brasileira, na medida em que a farinheira é um equipamento que simboliza a resistência e manutenção dessa cultura no atual modo de produção, marcado pela globalização, industrialização e urbanização, cenários em que práticas e costumes tradicionais são completamente ignorados e esquecidos.

\section{Conclusões}

O espaço rural brasileiro é composto por um mosaico cultural de saberes e práticas que revela aspectos de um modo de vida tradicional. No estado de São Paulo, são poucos os lugares em que esse universo se mantém, geralmente em vilas, bairros, sítios e pequenas propriedades rurais que não foram incorporadas pelos monocultivos de larga escala. Mesmo sendo produto da luta pela terra, os assentamentos rurais ainda guardam e mantêm vivos os fragmentos da cultura popular do campo. Nesse sentido, buscamos entender, neste artigo, os aspectos da cultura rural tradicional no assentamento de reforma agrária do município de Presidente Venceslau-SP, a partir da preservação do patrimônio imaterial e da reprodução de práticas tradicionais.

A partir da bibliografia e dos dados empíricos, verificamos em que medida o assentamento Primavera configura um espaço de reprodução e manutenção de práticas tradicionais do universo da cultura rural tradicional brasileira. A pesquisa nos possibilitou identificar sujeitos de múltiplas origens que reproduzem, em seu cotidiano, conhecimentos tradicionais relativos à alimentação, saúde, espiritualidade e sociabilidade.

Este trabalho propôs estudar os assentamentos rurais por meio de uma abordagem interdisciplinar e plural, visando a entender suas dimensões, a partir da cultura popular, dos saberes tradicionais e do patrimônio cultural. Na essência, os assentamentos rurais não se apresentam como espaços tradicionaia, como as comunidades indígenas, ribeirinhas e quilombolas; no entanto, detêm sujeitos que produzem e reproduzem, em seu cotidiano, práticas e saberes tradicionais, transformando os assentamentos em "lugares" (TUAN, 1983; SANTOS, 1997; SUERTEGARAY, 2001) carregado de memórias, identidades e culturas. Os sujeitos transmitem esses saberes por meio de gestos e da oralidade. Nesse sentido, acreditamos que o lugar se singulariza a partir de visões subjetivas vinculadas a percepções emotivas, a exemplo do sentimento topofilico (experiências felizes) aos quais se refere Tuan (1983). Para Santos (1997), o lugar constitui a dimensão da existência que se manifesta através "de um cotidiano compartido entre as mais diversas pessoas, firmas, instituições - cooperação e conflito são a base da vida em comum" (SANTOS, 1997, p. 94).

Partimos da hipótese de que, mesmo não sendo um espaço de origem tradicional, com famílias de múltiplas origens e trajetórias, os assentamentos rurais são espaços de produção, reprodução e manutenção 
da cultura rural tradicional. Os assentamentos rurais abrigam farinheiras, alambiques, benzedeiras, raizeiros e curandeiros que utilizam seus conhecimentos para sobreviverem. No caso estudado, analisou-se uma farinheira que se encontra em transição para técnicas mais modernas (com motores elétricos).

Conforme visto em D'Abadia e Almeida (2010), vivemos no tempo da ultramodernidade ou pós-modernidade, regido pela globalização, industrialização e urbanização. Nesse cenário, os conhecimentos e práticas tradicionais são descaracterizados e esquecidos pelo fluxo e pluralidade de informações e tendências. Nesse contexto, os assentamentos representam repositórios de fragmentos da cultura rural popular brasileira. $\mathrm{O}$ assentamento Primavera abarca pessoas que detêm esses conhecimentos. A pesquisa mostrou que os assentamentos rurais podem ser lidos de diversas maneiras, e não só pelos aspectos organizacionais do lote e da produção. Nossa proposta foi conhecê-los por um viés cultural, abarcando os saberes tradicionais e o patrimônio cultural.

Portanto, entendemos que os assentamentos são espaços de manutenção das práticas tradicionais advindas de comunidades rurais, que resistem ao avanço da modernidade no território brasileiro. Esses sujeitos detêm um modo de ser, e saber-fazer sobre o meio natural e sobrenatural, no caso as benzedeiras, curandeiros e raizeiros.

Nos estudo de assentamentos de reforma agrária, encontramos um mosaico de culturas, com sujeitos de múltiplas origens e trajetórias. Em campo, deparamo-nos com diferentes histórias de vida: ex-trabalhadores rurais, ex-meeiros, ex-arrendatários, trabalhadores urbanos, filhos e netos de caipiras nômades, que demonstram, em sua prática cotidiana, uma pluralidade de vivências, apresentando-nos questões que transcendem ao aspecto econômico das análises (MACIEL, 2009).

Entende-se esse novo modo de vida como espaço de articulação de valores e tradições, construção de novos laços sociais e tomada de decisões (MACIEL, 2009). Os assentamentos de reforma agrária guardam sujeitos que produzem, em seu cotidiano, um modo de vida ligado à cultura rural tradicional. A partir da pesquisa bibliográfica e do universo empírico, verificamos que esses aspectos relacionados à cultura caipira e rural tradicional se mantêm resistentes nos assentamentos de reforma agrária. No entanto, a transmissão desse patrimônio está em parte ameaçada. Logo, torna-se importante o fortalecimento de espaços e momentos nos quais essas tradições (patrimônio imaterial) possam ser preservadas.

\section{REFERÊNCIAS}

ARAÚJO, J. S. P; LOPES, G. A. Produção de farinha de mandioca na agricultura familiar. Niterói: Programa Rural, 2008.

BARONE, L. A.; OLIVEIRA, F. H. F. Os assentamentos de reforma agrária e a refuncionalização de estruturas arquitetônicas rurais: um estudo de caso no Pontal do Paranapanema. Retratos de assentamentos, Araraquara, v. 17, n. 1, p. 93-116, 2014.

CANDIDO, A. Os parceiros do Rio Bonito. São Paulo: Editora 34. 1987.

CASCUDO, L. C. Dicionário do folclore brasileiro. 10. ed. São Paulo: Global, 2000.

CHISTÉ, R. G.; GOHEN, K. O. Efeito do processo de fabricação da farinha de mandioca. Belém: Embrapa Amazônia Oriental, 2006.

D‘ABADIA, M. I. V.; ALMEIDA, M. G. Festas religiosas e pós-modernidade. Geonordeste, São Cristóvão, ano XX, n. 2, p. 57-80, 2010.

\section{FACCIO, N. B. Arqueologia guarani na área do} Projeto Paranapanema: estudo dos sítios de Iepê, SP. Tese (Livre-docência em Arqueologia Brasileira) Museu de Arqueologia e Etnologia, Universidade de São Paulo, São Paulo, 2011.

FUNARI, P. P. Arqueologia. São Paulo: Contexto, 2006.

\section{GHIRARDELLO, N; SPISSO, B. Patrimônio históri- co: como e por que preservar. Bauru: Canal 6, 2008.}

GOMES, T. P. S. Das receitas às práticas de benzedura e cura: uma etnografia dos saberes tradicionais de mulheres assentadas. Retratos de assentamentos, Araraquara, v. 14, n. 1, p. 33-74, 2011.

MACIEL, M. C. Tupanciretã: Deus passou por aqui: um estudo sobre as relações entre movimentos sociais nos assentamentos rurais Primavera e Tupanciretã no Pontal do Paranapanema/SP. Tese (Doutorado em Sociologia) - Faculdade de Filosofia Letras e Ciências Humanas, Universidade de São Paulo, São Paulo, 2011. 
OLIVEIRA, F. H. F. Cultura no espaço rural: estudo do patrimônio cultural e dos saberes tradicionais nos assentamentos do Pontal do Paranapanema. Relatório Final de Pesquisa de Iniciação Científica PIBIC/CNPq. Faculdade de Ciência e Tecnologia, Universidade Estadual Paulista, Presidente Prudente, 2014.

\section{Aspectos da cultura rural tradicio-}

nal na Reforma Agrária: um estudo nos assentamentos de Presidente Venceslau-SP. Monografia (Bacharelado em Geografia) - Faculdade de Ciência e Tecnologia, Universidade Estadual Paulista, Presidente Prudente, 2015.

QUEIROZ, M. I. P. O campesinato brasileiro. Petrópolis: Vozes, 1973.

SANTOS, M. A natureza do espaço. Técnica e tempo, razão e emoção. São Paulo: EDUSP, 1997.

SILVA, F. A. A tecnologia e seus significados. In: WORKSHOP ARQUEOLÓGICO DE XINGÓ, 2.,
2002, Canindé do São Francisco. Anais... Canindé de São Francisco: Museu de Arqueologia de Xingó, 2002.

SUERTEGARAY, D. M. A. Espaço geográfico uno e múltiplo. Revista electrónica de geografía y ciencias sociales, Barcelona, n. 93, 15 jul. 2001. Disponível em: <http://www.ub.edu/geocrit/sn-93. htm>. Acesso em: 22 set. 2016.

TUAN, Y. F. Espaço e lugar: a perspectiva da experiência. São Paulo: Difel, 1983.

WANDERLEY, M. N. B. Conferências magistrais: reforma agrária e o modelo político de sociedade. In: BERGAMASCO, S. M. Assentamentos rurais no século XXI: temas recorrentes. INGRA: São Paulo, 2011.

WHITAKER, D. G. A. et al. A transcrição da fala do homem rural: fidelidade ou caricatura? In: Sociologia rural: questões metodológicas emergentes. Presidente Venceslau: Letras a margem, 2002. 